\title{
4 Social aspects of women's agribusiness in times of COVID-19 in the Central Highlands of Vietnam
}

\author{
Nozomi Kawarazuka and Pham Thi Hoa
}

\section{Introduction}

Vietnam is considered one of the most successful countries in controlling the COVID-19 pandemic. By March 24, 2021, there were 2,576 cases and 35 deaths (Worldometers, 2021). We feel safe in Vietnam. Watching news on the global pandemic is like watching a scary movie from a different planet. Nevertheless, many Vietnamese people have been directly and indirectly affected by the pandemic. According to the General Statistics Office, 32.1 million Vietnamese workers either lost their jobs or had their working hours/salaries reduced in 2020 (Nguyen, 2021). Furthermore, over 75,000 Vietnamese were repatriated from 59 countries with 260 repatriation flights in 2020. Returned migrants included 219 male construction workers from Equatorial Guinea, of whom 129 were COVID positive, over 200 pregnant women from Taiwan, 53 infants from South Korea, and nearly 200 monks and nuns from India (Anh, 2020). These statistics demonstrate how intertwined the lives of Vietnamese workers are with the global economy.

At the global level, this pandemic has reconfirmed that current expression of neoliberal capitalism is inherently unequal and persistently excludes marginalized social groups during crisis (e.g., Stevano et al., 2021). We observe its wide range of economic and social consequences on marginalized people all over the world, especially women and children from disadvantaged backgrounds. The pandemic uncovered contradictions and conflicts within neoliberal capitalism for global growth and international development. Clearly productivity- and profit-focused economies are incompatible with equality, social welfare, and environmental sustainability. An urgent need exists for alternatives, including agrifood systems, that produce equitable distribution and sustainable utilization of labor and natural resources.

This chapter illustrates three women agribusiness owners in the Central Highlands whose business goals are not solely about profit and productivity, but more about social development and environmental sustainability. 


\section{Nozomi Kawarazuka and Pham Thi Hoa}

The study draws on feminist approaches to entrepreneurship in terms of concepts and methodologies (Ahl, 2006; Hughes et al., 2012). We observe the social aspects of their businesses that determined the impacts of and responses to the COVID-19 pandemic. Their narratives suggest ideas to critically think what future alternative resilient agribusiness should aim for, and how social research can contribute to enriching understanding of women entrepreneurs.

\section{Local context and methods}

Lam Dong province is located in the Central Highlands of Vietnam and is well known for high-quality agricultural produce: vegetables, roots, tubers, flowers, fruits, coffee, tea, and dairy. Many Vietnamese consumers associate the name of the provincial capital, Da Lat city, with positive images of clean, high-quality, and fresh produce. The outskirts of Da Lat city offer an all-embracing view of greenhouses covering hundreds of hectares of irrigated farmlands (Figures 4.1 and 4.2). The province also has forest

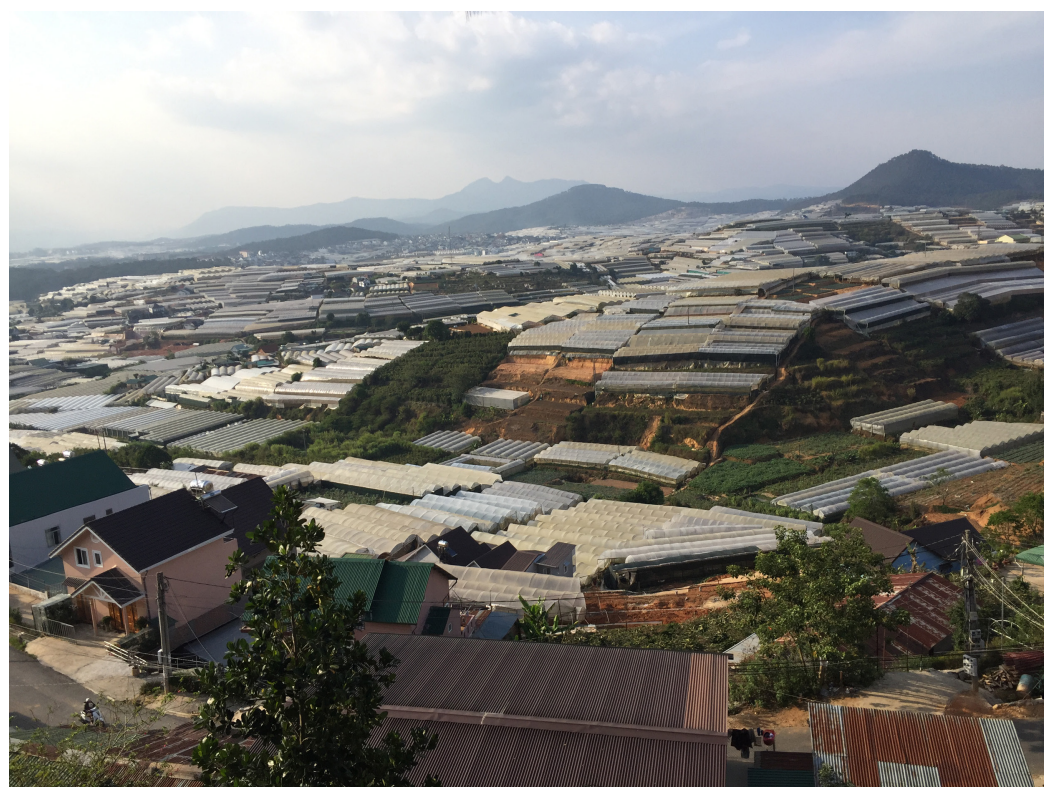

Figure 4.1 The view of greenhouses from the outskirts of Da Lat city (Pham Thi Hoa). 


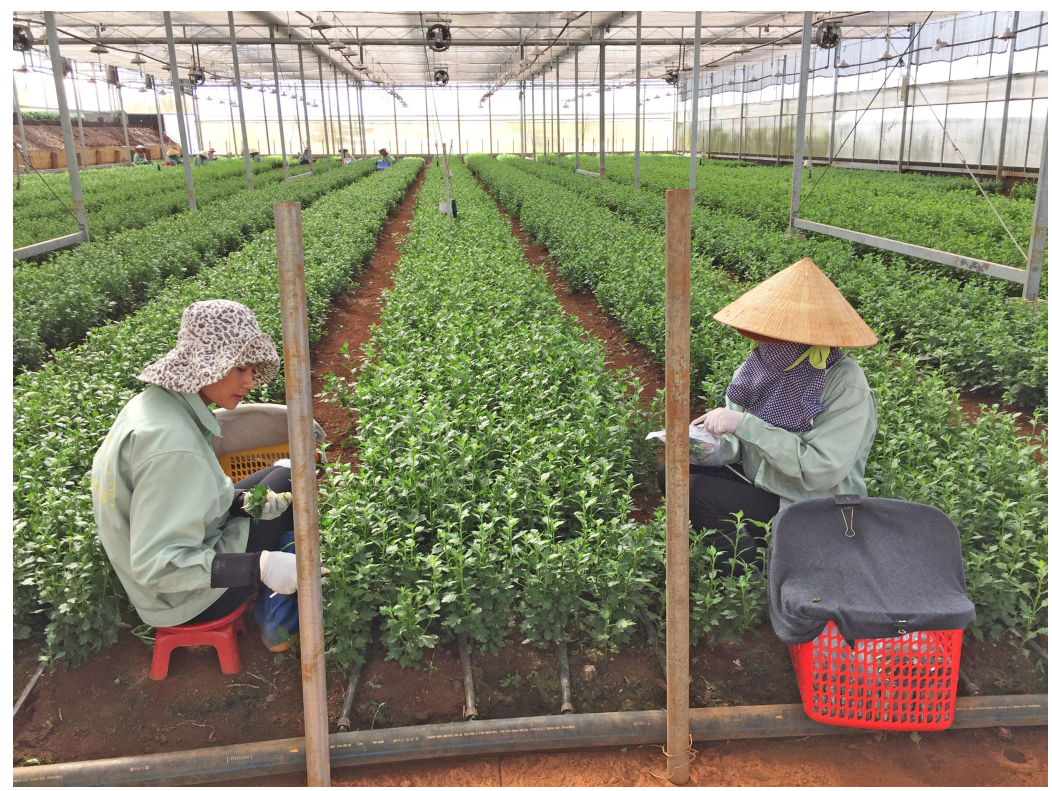

Figure 4.2 Women work in a greenhouse for chrysanthemum cultivation, Lam Dong province, Vietnam (Pham Thi Hoa).

conservation areas where ethnic minority rangers monitor illegal wildlife poaching and maintain forests by planting trees.

The economic impact of COVID-19 on the Lam Dong horticultural industry was particularly serious for the cut-flower market, while impacts on other horticultural produce, especially the domestic market, remained relatively small and short. At the beginning of the pandemic, when the government closed borders, those selling vegetables and flowers for export lost their market. In the summer of 2020, when Vietnam had an outbreak in the central city of Da Nang, the horticultural sector was more significantly affected by the closure of domestic transport routes and reduced consumer demand especially from events, festivals, hotels, and domestic tourism. Agribusiness owners in Lam Dong adapted rapidly by looking for new markets online and finding retailers and individual consumers through Facebook, laying off some workers and shifting crops from export to domestic markets to adapt to domestic needs. The ability to adapt to change varies. Some agribusiness companies and their contract farmers/workers and traders were affected more seriously than others. 
Three women respondents were selected from the list of 11 women agribusiness owners whom the second author met earlier during her study on the impact of COVID-19 on agriculture. The three women have different business histories and family backgrounds. Each agribusiness owner is unique, and their stories are not generalizable, yet their narratives illuminate agribusiness from women's perspectives. Prior to the interviews, respondents shared information about their agribusiness. In-depth interviews were conducted in late February 2021 in their homes or gardens. The first author participated in the interview online while the second author had face-to-face interactions. Each interview took one to one and a half hours using seven guiding questions. Topics included family, life history, business history, their informal support, relationships with employees, ethics, values and goals of their business, and their principles in decision-making related to their agribusiness. The interviewer took care to create a natural conversation format. Interviews were not recorded but documented as field notes. A thematic content analysis identified key non-economic aspects of agribusiness commonly observed among three respondents.

\section{Stories}

\section{Respondents' responses to COVID-19}

Lan, ${ }^{1} 54$, started her small agribusiness with coffee trees and tomatoes in 1990 when she married and had a first daughter. In 1992, she resigned from her professional job as a gynecologist to focus on her agribusiness. Over 30 years, she expanded her business to 27 hectares, hiring 100 workers, some of whom have worked for her for over 20 years. Her husband, a telecommunication engineer, resigned from his job and joined her business in 1999. Currently, they grow flowers and vegetables for domestic and global markets such as Japan, Singapore, and the Netherlands.

For Lan, this crisis is not the first time she faced a challenge. In 1999, with a sharp decline in global coffee prices, she cut down her trees and turned to flower production. This time with COVID-19, fresh-flower sales were seriously affected by reduced demand from hotels, events, and festival organizers in both domestic and global markets. She turned 30 percent of her flower farms over to vegetables, with the same brave and immediate decision as she had taken many years previously. This strategy worked well. Over the 2020 COVID-19 period, her greenhouse vegetable area expanded from 5 to 7 ha as she saw strong consumer demand for certified clean and safe vegetables. Lan also asked her daughter to establish online Facebook trading for the flowers to explore new business partners, 
particularly retailers rather than wholesalers. This enabled her to diversify her markets and find new regular customers, as a positive legacy of COVID-19.

Bich, 71, started farming in 2010 by renting a small farmland, in the year she lost everything: her real estate business went bankrupt; she sold her land; and she divorced her husband. She started farming for survival with no money, no land, no family support, and no knowledge of agribusiness. After three years, she began a hydroponic clean vegetable producing system through technical support from a Dutch private plant-breeding company (Rijk Zwaan). Currently she owns 1.8 ha of hydroponics cultivation areas and produces 180 tons of vegetables annually. She eventually gained a strong positive reputation and the trust of major local and foreign-invested supermarkets with a successful branding of her vegetables as safe and clean produce. She hires 20 workers, 70 percent of whom are ethnic minorities.

Bich planned to export her fresh vegetable to Japan during the 2020 Tokyo Olympics and in 2018 two Japanese middlemen visited her farms. She was excited and prepared for export. However, because of the pandemic, the Olympic games were postponed. Domestic demand in Da Nang also declined for two months during the second COVID-19 wave. She had nowhere to sell and had to reduce production. While her profit has reduced significantly, she kept her 20 workers' salaries at the same level and only reduced their bonus at the end of the year.

Hang, 42, a civil servant, produces environmentally sustainable coffee by hiring local farmers and sells high-quality roasted coffee directly to domestic consumers and baristas in Hanoi and Ho Chi Minh city. She started growing coffee in 2013 after she divorced her husband. With a minimum investment from her savings, she rented 2 ha of farm and planted local variety coffee trees, which she grows without chemicals. She eventually expanded her farms to 5 ha and tried many methods to roast coffee beans. Currently she hires five farmers and produces 2 tons of coffee beans per year. Her main job remains being a civil servant in Da Lat.

Like the horticulture and flower industries, around the world the coffee industry has been affected by COVID-19. Many Vietnamese coffee farmers have been unable to sell all their beans and have reduced incomes. Hang's coffee business is different. Her business and her farmers were not affected. Instead, demand from individual consumers increased during the stay-home period because her business and her coffee farmers are independent from the global coffee market.

Why did Lan and Bich not reduce their workers' salaries or lay some off as many companies have done? Why was Hang's business so strong compared to the global coffee industry in general? In the following sections we explore social aspects of their business management to understand 
the strategies that might have helped them to navigate challenges during COVID-19.

\section{Informal support for building trust and making economic gains}

These three women commonly utilize informal social networks to receive technical and psychological support, which is a foundation for building social trust and making economic gains for resiliency to crises such as the pandemic. Prior to their agribusiness, they had no knowledge or skills of agriculture or entrepreneurism. Lan was a gynecologist who became an English teacher. Bich's professional career was in real estate. Hang is a civil servant. However, they each utilized their social networks of friends, neighbors, and foreigners who provide psychological and technical support. We observed that they are open to new technologies and practices and have strong determination to continually innovate.

At the beginning of her business, Lan visited the largest flower garden in Da Lat with her husband to learn how to grow flowers. She soon realized the importance of quality seeds. She researched and identified companies in the Netherlands and imported her first batch of 1,500 seedlings in 1999. She then contacted a food consultancy company in Vietnam (Fresh Studio) and bought high-quality clean seed potatoes from them. She also received funds for training in the Netherlands and learnt Dutch technology, investing in a laboratory to propagate flowers by the in-vitro method. She established a demonstration area to share her technology with visitors, students, and young business owners. Although she had little knowledge and skills in horticultural business, informal social networks enabled her enterprise to grow and be resilient to shocks.

Bich's skills and knowledge of farming derived from childhood experience helping on the family farm. She aimed to produce clean and safe vegetables. She joined a training program in Malaysia organized by Rijk Zwaan, where she encountered hydroponic vegetable cultivation techniques. The hydroponic system does not use pesticides and has no waste, which ideally suited her aims. Upon returning from the training, she was determined to establish this system in her farm. It was her determination that attracted the Dutch seed company to provide long-term technical support for her business, leading to successful branding of her agricultural produce, which is a key for surviving in times of this crisis.

Hang did not have support from her family. Her Vietnamese friend in the USA taught her about coffee through online conversations. She was inspired by him and decided to try. She also reached out to another Vietnamese friend in Norway who produces organic fertilizers and imported them. She keeps learning about coffee online with other people who love coffee. During the 
interview, we were amazed by her in-depth knowledge about world coffee-tree varieties, and coffee beans and their differences in flavor. The fact that her enterprise and market were initiated from her social networks is a strength, especially during COVID-19, as her business is unaffected by global coffee markets.

Vietnamese people often believe entrepreneurs must have strong connections with politically and economically powerful people through families and relatives. Women's success in business is rarely viewed as arising from their own capacity, hard work, and effort but through their husbands' connections and financial support. The women in this chapter, however, show that passive connections given by family and relatives are not essential, but active connections developed by individual effort, interpersonal skills, and strong determination are. Longstanding cultivation of relationships helped these women to initiate and grow their enterprises, enabling them to navigate challenges during COVID-19.

\section{Relationship of trust and worker well-being}

Here, we move beyond the stories of COVID-19 and explore underlying business principles, which provide ideas of possible post-COVID-19 agribusiness models for women entrepreneurs. Agribusiness is often evaluated from an economic aspect, such as the scale of investment and production and number of employees. However, in this approach, those who use different criteria are under-evaluated. We now look at the three women's business principles.

Hang has three business principles: increasing coffee producers' value; reducing coffee waste by focusing on quality; and creating a business model of environmentally sustainable coffee production. She achieves this by building relationships of trust with her coffee producers with similar beliefs. She thinks that mass production and consumption of coffee typically undervalue and exploit producers, leaving them with high dependency on agricultural inputs and global coffee markets. In contrast, her business focuses on ensuring production quality depending on producers' quality of work and their faith. Relationships of trust is key for her business, both with producers and consumers.

Bich said that, at her age, she is not intending to earn more money or expand her business to increase profit. She is most proud that she employs ethnic minority people as workers on her farms as they tend to be poorer and marginalized compared to the ethnic majority. They no longer need to depend on forests as a source of income, which in turn contributes to forest conservation. Their children go to school and may even reach higher education, a transformative change. She is thinking of handing over her business 
to someone with a similar philosophy. She dreams before retiring to plant many flowering cherry trees in Lam Dong forests, indicating that her interests go far beyond securing personal profits and economic status.

"The profit is not for me. It's for my employees and for the society," Lan said immediately when we asked about her business goals. She prioritizes making her employees happy. She provides houses for her workers' families, offers loans for their children's university education, and organizes an annual company trip to a beach resort. Although some staff leave her employ to take their next career steps, she believes that investing in employees is key as they are assets of her company. She also keeps her company open to tourists, investors, and other entrepreneurs, providing space to share her experiences. As such, she gains trust from her employees, traders, and consumers.

The combination of economic savvy, close attention to building and maintaining social networks, and catering explicitly to worker well-being enabled them to survive during COVID-19, and even come out stronger for Lan. When we explore social, rather than economic, dimensions of agribusiness, the strengths of women's agribusiness in this crisis are illuminated.

\section{Concluding remarks}

This chapter illustrated the stories of three women agribusiness owners to understand social dimensions of entrepreneurship from women's perspectives. Feminist scholars point out that women entrepreneurs are often under-evaluated in male-orientated entrepreneur research as those studies tend to focus exclusively on quantity and economic aspects of entrepreneurship (Ahl, 2006; Hughes et al., 2012). Similarly, research on the impact of COVID-19 on agribusiness or agriculture tends to start from investigating economic impacts. The pandemic's economic impact is undeniable, and women entrepreneurs face many more challenges in this respect. However, women entrepreneurs have strengths in management and handling of business in times of crisis, in which their ethics, social values, and goals of agribusiness are vital.

Key characteristics of the women's agribusinesses we identified are social responsibility, open-mindedness, knowledge-sharing, environmental sustainability, a relationship of trust, informal networks, and online tools. While their businesses are global, their efforts are locally orientated, and their goals are associated with local, not global, stakeholders contributing to making their business resilient to the global crisis.

The pandemic, as an environmental and global problem, tells us that the globalization we have experienced in the past decades is fragile. The three women's approaches to agribusiness are alternative models to the 
profit-orientated capitalist economy, which are compatible with social and gender equality and environmental sustainability.

\section{Acknowledgments}

We thank the three women agribusiness owners for sharing their experiences. We are grateful to Cathy Farnworth and Paige Caroline Castellanos for their valuable comments on earlier drafts of this manuscript. This study was funded by CGIAR including the GENDER platform, the research program of Roots, Tubers and Bananas, and the research program of Policies, Institutions, and Markets led by the International Food Policy Research Institute. The opinions expressed here belong to the authors, and do not necessarily reflect those of CGIAR. This study was conducted within the Meryl Williams Fellowship program, funded by ACIAR.

\section{Note}

1 Names are changed to protect privacy.

\section{References}

Ahl, H. (2006). Why research on women entrepreneurs needs new directions. Entrepreneurship Theory and Practice, 30(5), 595-621.

Anh, P. (2020). 75,000 Vietnamese repatriated amid coronavirus pandemic. Available at: https:/e.vnexpress.net/news/news/75-000-vietnamese-repatriated -amid-coronavirus-pandemic-4213029.html.

Hughes, K. D., Jennings, J. E., Brush, C., Carter, S., \& Welter, F. (2012). Extending women's entrepreneurship research in new directions. Entrepreneurship Theory and Practice, 36(3), 429-442.

Nguyen, L. (2021). Hanoi's Covid-19 fight leaves street food vendors in the lurch [Online]. Available at: https://e.vnexpress.net/news/life/trend/hanoi-s-covid-19 -fight-leaves-street-food-vendors-in-the-lurch-4242668.html.

Stevano, S., Franz, T., Dafermos, Y., \& Van Waeyenberge, E. (2021). COVID-19 and crises of capitalism: intensifying inequalities and global responses. Canadian Journal of Development Studies/Revue canadienne d'études du développement, 42(1-2), 1-17.

Worldometers. (2021). Covid live update [Online]. Available at: https://www .worldometers.info/coronavirus/ (Accessed March 24, 2021) 
